\title{
Bureaucratic landscapes: Interagency cooperation and the preservation of biodiversity
}

\section{Murray B. Rutherford}

(C) Springer Science + Business Media B.V. 2006

Policy Sciences (2005) 38: 195-200

DOI: 10.1007/s11077-005-2478-z

Unfortunately the data displayed on Springerlink.com is incorrect. Small Murray Rutherford should be Murray B. Rutherford. 